\title{
Clinical Study \\ Retinal Nerve Fiber Layer Thickness in Women with Polycystic Ovary Syndrome
}

\author{
Mehmet Demir, ${ }^{1}$ Dilek Guven, ${ }^{1}$ Arzu Koc, ${ }^{2}$ Savas Ozdemir, ${ }^{2}$ and Efe Can ${ }^{1}$ \\ ${ }^{1}$ Department of Ophthalmology, Sisli Etfal Training and Research Hospital, Sisli, 34400 Istanbul, Turkey \\ ${ }^{2}$ Department of Obstetrics and Gynecology, Sisli Etfal Training and Research Hospital, Sisli, 34400 Istanbul, Turkey
}

Correspondence should be addressed to Mehmet Demir; drmehmetfe@hotmail.com

Received 24 July 2013; Accepted 30 October 2013

Academic Editor: Michel Eid Farah

Copyright (C) 2013 Mehmet Demir et al. This is an open access article distributed under the Creative Commons Attribution License, which permits unrestricted use, distribution, and reproduction in any medium, provided the original work is properly cited.

\begin{abstract}
Aim. To compare the retinal nerve fiber layer (RNFL) thickness between women with polycystic ovary syndrome (PCOS) and healthy women. Materials and Methods. The study included 88 eyes of 44 women (group 1) with PCOS and 84 eyes of 42 healthy women (group 2). In all subjects, the RNFL and ganglion cell complex (GCC) thicknesses were measured by optical coherence tomography (OCT). In addition, visual acuity (VA), intraocular pressure (IOP), refractive errors, central macular thickness (CMT), central corneal thickness (CCT), and excavation of optic disc were evaluated in all subjects. Results. Mean values of GCC, IOP, VA, CMT, CCT, and refractive errors were similar between the 2 groups. The average RNFL, superior average RNFL, and inferior average RNFL thicknesses were higher in subjects with PCOS than in healthy subjects $(P=0.003, P=0.012$, and $P=0.009)$, respectively. Conclusion. The average RNFL, superior average RNFL, and inferior average RNFL thicknesses in women with PCOS were significantly higher than in healthy women.
\end{abstract}

\section{Introduction}

Polycystic ovary syndrome (PCOS) is one of the most common endocrinopathies among women in the reproductive age, and it affects $5-7 \%$ of this group [1]. It is characterized by an irregular menstrual cycle, ovulatory dysfunction, and hyperandrogenism [2,3]. Metabolic alterations, insulin resistance, and obesity are often in the patient with PCOS [4]. More than $40 \%$ of women with PCOS might develop impaired glucose tolerance or type 2 diabetes mellitus $[5,6]$. Optical coherence tomography (OCT) is a noninvasive, noncontact technique that utilizes near infrared, low coherence light passing through a Michelson interferometer to obtain two-dimensional images of the retina, the resolution of which is approximately $5-10 \mu \mathrm{m}$ in the axial plane [7].

\section{Materials and Methods}

This study included 88 eyes of 44 women (group 1) with PCOS and 84 eyes of 42 healthy women (group 2). The women with PCOS were recruited from among those who visited the Department of Obstetrics and Gynecology. The women with PCOS were selected according to the Androgen Excess and PCOS Society (AES 2006) criteria that included hyperandrogenism, ovulatory dysfunction, and/or polycystic ovary morphology [8]. The women who had a systemic problem other than PCOS were not included in the study. The control group included healthy women who had no ophthalmologic and systemic disorders. Informed consent was obtained from all included subjects, and the study protocol was approved by the local Ethical Committee. Further, all procedures were performed in accordance with the Declaration of Helsinki. The anterior-posterior segments, visual acuity (VA), intraocular pressure (IOP), central macular thickness (CMT), central corneal thickness (CCT), and cup/disc ratio (c/d) were examined for all patients in the ophthalmology clinic (Table 1). In addition, superior nasal (SN) RNFL, nasal upper (NU) RNFL, nasal lateral (NL) RNFL, inferior nasal (IN) RNFL, inferior temporal (IT) RNFL, temporal lateral (TL) RNFL, temporal upper (TU) RNFL, superior temporal (ST) RNFL, average (Avg.) RNFL, superior (Sup.) Avg. RNFL, inferior (Inf.) Avg. RNFL, Avg. ganglion cell complex (GCC), Sup. GCC and Inf. GCC were measured (Table 2). 
TABLE 1: Values of age, VA, IOP, CMT, and CCT of study and control groups.

\begin{tabular}{lccc}
\hline & $\begin{array}{c}\text { Study group } \\
\text { (44 patients; } 88 \\
\text { eyes) }\end{array}$ & $\begin{array}{c}\text { Control group } \\
(42 \text { patients; } 84 \\
\text { eyes })\end{array}$ & $P^{\dagger}$ \\
\hline Age $($ mean \pm SD) & $24.55 \pm 5.67$ & $27.29 \pm 5.9$ & 0.173 \\
VA $(\operatorname{logMAR})$ & 0.00 & 0.00 & $>0.999$ \\
IOP $(\mathrm{mm} \mathrm{Hg})$ & $16.13 \pm 2.34$ & $15.57 \pm 3.33$ & 0.423 \\
CMT $(\mu \mathrm{m})$ & $218.5 \pm 32.13$ & $228.04 \pm 19.56$ & 0.165 \\
CCT $(\mu \mathrm{m})$ & $556.75 \pm 30.29$ & $551.88 \pm 35.91$ & 0.556 \\
C/D & $0.09 \pm 0.16$ & $0.09 \pm 0.14$ & $0.673^{*}$ \\
\hline
\end{tabular}

${ }^{\dagger}$ Independent $t$-test, ${ }^{*}$ Mann-Whitney $U$ test, VA: visual acuity, logMAR: logarithm of the minimum angle of resolution, IOP: intraocular pressure, CMT: central macular thickness, CCT: central corneal thickness, and C/D: cup/disc ratio.

TABLE 2: RNFL $(\mu \mathrm{m})$ and GCC $(\mu \mathrm{m})$ analysis in both groups.

\begin{tabular}{lccc}
\hline & $\begin{array}{c}\text { Study group } \\
(88 \text { eyes })\end{array}$ & $\begin{array}{c}\text { Control group } \\
(84 \text { eyes })\end{array}$ & $P^{\dagger}$ \\
\hline SN RNFL & $126.18 \pm 21.34$ & $115.39 \pm 18.85$ & 0.032 \\
NU RNFL & $84.93 \pm 18.13$ & $81.14 \pm 17$ & 0.379 \\
NL RNFL & $73.8 \pm 13.06$ & $71.36 \pm 15.15$ & 0.471 \\
IN RNFL & $130.25 \pm 23.32$ & $118.25 \pm 21.19$ & 0.031 \\
IT RNFL & $150.43 \pm 14.78$ & $145.39 \pm 14.26$ & 0.157 \\
TL RNFL & $79.14 \pm 16.14$ & $75.57 \pm 10.45$ & 0.303 \\
TU RNFL & $88.16 \pm 13.37$ & $88.54 \pm 12.62$ & 0.906 \\
ST RNFL & $145 \pm 16.07$ & $135.96 \pm 15.73$ & 0.022 \\
Avg. RNLF & $109.98 \pm 8.19$ & $103.96 \pm 8.28$ & 0.003 \\
Sup. Avg. RNFL & $111.55 \pm 10.36$ & $105.39 \pm 9.11$ & 0.012 \\
Inf. Avg. RNFL & $108.32 \pm 8.49$ & $102.64 \pm 9.08$ & 0.009 \\
Avg. GCC & $98.09 \pm 7.33$ & $95.68 \pm 5.11$ & 0.133 \\
Sup. GCC & $97.34 \pm 7.68$ & $95.36 \pm 5.3$ & 0.236 \\
Inf. GCC & $98.84 \pm 7.33$ & $96.11 \pm 5.16$ & 0.09 \\
\hline
\end{tabular}

${ }^{\dagger}$ Independent $t$-test, RNFL: retinal nerve fiber layer, GCC: ganglion cell complex, SN: superior nasal, UN: nasal upper, NL: nasal lateral, IN: inferior nasal, IT: inferior temporal, TL: temporal lateral, TU: temporal upper, ST: superior temporal, Avg: average, Sup: superior, Inf: inferior, RNFL: retinal nerve fiber layer, GCC: ganglion cell complex, and UP: upper.

Exclusion criteria for both groups included presence of glaucoma, ocular hypertension (IOP $>21 \mathrm{mmHg}$ ), diabetes mellitus, retinal vasculitis or dystrophy, and history of intraocular surgery, amblyopia, or refractive errors more than \pm 1.00 diopter spherical equivalent. RNFL, CMT, CCT, and GCC thicknesses were measured using OCT (RTVue-100; Optovue, Fremont, CA). CCT was measured by ultrasonic pachymeter in all patients. Independent $t$-test and MannWhitney $U$ test were used for statistical evaluation. A $P$ value of $<0.05$ was considered statistically significant.

\section{Results}

The mean age (mean \pm SD) of the PCOS group was $24.55 \pm$ 5.67 (range: 18-34) years and that of the control group was $27.29 \pm 5.9$ (range: $18-33)$ years $(P=0.173)$.
Mean VA, IOP, CMT, CCT, and C/D were similar in both groups (Table 1). The RNFL average was $109.98 \pm 8.19 \mu \mathrm{m}$ in the study group and $103.96 \pm 8.28$ in the control group $(P=$ $0.003)$. The average superior RNFL thickness was $111.55 \pm$ $10.36 \mu \mathrm{m}$ in the study group and $105.39 \pm 9.11 \mu \mathrm{m}$ in the control group $(P=0.012)$; the average inferior RNFL thickness was $108.32 \pm 8.49 \mu \mathrm{m}$ in the study group and $102.64 \pm 9.08 \mu \mathrm{m}$ in the control group $(P=0.009)$. Also mean SN RNFL, IN RNFL, and ST RNFL were thicker in women with PCOS than in healthy women (Table 2).

\section{Discussion}

We aimed to compare the measurements of RNFL, IOP, CCT, and GCC in women with PCOS and healthy women.

In this study, which is the first of its kind, we have analyzed the thicknesses of RNFL, GCC, CCT, CMT, and the IOP in women with PCOS and compared it with healthy women. It is known that in patients with PCOS, the eye also gets affected. Typically, the tear function, drainage and osmolarity $[9,10]$, meibomian gland function [11], and ocular surface [12] were affected by PCOS. OCT has been used for estimation of RNFL and GCC thicknesses [13-18]. High nerve fiber density was found in PCOS patients [18]. High level of nerve growth factor (NGF) was reported in women with PCOS [19]. Androgens and nerve growth factor have trophic actions on nerves [20-22]. Insulin resistance that can cause diabetic eye changes in women with PCOS. RNFL thickness was thicker in women with PCOS than in healthy women in superior nasal, inferior nasal and superior temporal quadrants. Also average RNFL thickness and average superior and average inferior quadrants RNFL thicknesses were significantly thicker in women with PCOS than in healthy women. The limitations of this study were small sample size, lack of pathologic examination, and inability to reason the results. Studies with larger numbers of participants are required to clarify the clinical and pathophysiological significance of RNFL thickness in women with PCOS. The results of this study can be taken into account in evaluating patients who had PCOS and glaucoma or multiple sclerosis.

In summary, we found that the average RNFL, average superior and inferior RNFL, SN RNFL, IN RNFL, and ST RNFL thicknesses were significantly higher in women with PCOS than in healthy women. We have interpreted that excess androgens and NGF cause an increase in RNFL thickness in women with PCOS.

\section{Conflict of Interests}

The authors declare that there is no conflict of interests regarding the publication of this paper.

\section{References}

[1] D. A. Ehnnann, "Polycystic ovary syndrome," The New England Journal of Medicine, vol. 352, pp. 1223-1236, 2005.

[2] R. J. Norman, D. Dewailly, R. S. Legro, and T. E. Hickey, "Polycystic ovary syndrome," The Lancet, vol. 370, no. 9588, pp. 685-697, 2007. 
[3] P. Acién, F. Quereda, P. Matallín et al., "Insulin, androgens, and obesity in women with and without polycystic ovary syndrome: a heterogeneous group of disorders," Fertility and Sterility, vol. 72, no. 1, pp. 32-40, 1999.

[4] R. Pasquali and A. Gambineri, "Glucose intolerance states in women with the polycystic ovary syndrome," Journal of Endocrinological Investigation, vol. 36, pp. 648-653, 2013.

[5] D. A. Ehrmann, R. B. Barnes, R. L. Rosenfield, M. K. Cavaghan, and J. Imperial, "Prevalence of impaired glucose tolerance and diabetes in women with polycystic ovary syndrome," Diabetes Care, vol. 22, no. 1, pp. 141-146, 1999.

[6] K. Lakhani, G. M. Prelevic, A. M. Seifalian, W. U. Atiomo, and P. Hardiman, "Polycystic ovary syndrome, diabetes and cardiovascular disease: risks and risk factors," Journal of Obstetrics and Gynaecology, vol. 24, no. 6, pp. 613-621, 2004.

[7] T. Pedut-Kloizman, H. M. Pakter, J. S. Schuman, J. C. Szwartz, and M. R. Hee, "Ophthalmic diagnosis using optical coherence tomography," Ophthalmology Clinics of North America, vol. 11, no. 3, pp. 465-486, 1998.

[8] J. Johansson and E. Stener-Victorin, "Polycystic ovary syndrome: effect and mechanisms of acupuncture for ovulation induction," Evidence-Based Complementary and Alternative Medicine, vol. 2013, Article ID 762615, 16 pages, 2013.

[9] H. Coksuer, F. Ozcura, F. Oghan, B. Haliloglu, and S. Karatas, "Effects of hyperandrogenism on tear function and tear drainage in patients with polycystic ovary syndrome," Journal of Reproductive Medicine for the Obstetrician and Gynecologist, vol. 56, no. 1-2, pp. 65-70, 2011.

[10] T. Gonen, C. Celik, M. Oznur et al., "Tear osmolarity and ocular surface changes in patient with polycystic ovary syndrome," Current Eye Research, vol. 38, no. 6, pp. 621-625, 2013.

[11] G. F. Yavas, F. Ozturk, T. Kusbeci et al., "Meibomian gland alterations in polycystic ovary syndrome," Current Eye Research, vol. 33, no. 2, pp. 133-138, 2008.

[12] S. Bonini, F. Mantelli, C. Moretti, A. Lambiase, S. Bonini, and A. Micera, "Itchy-dry eye associated with polycystic ovary syndrome," American Journal of Ophthalmology, vol. 143, no. 5, pp. 763-771, 2007.

[13] T. Redmond, R. S. Anderson, R. A. Russell, and D. F. GarwayHeath, "Relating retinal nerve fiber layer thickness and functional estimates of ganglion cell sampling density in healthy eyes and in early glaucoma," Investigative Ophthalmology \& Visual Science, vol. 54, no. 3, pp. 2153-2162, 2013.

[14] G. Wollstein, L. Kagemann, R. A. Bilonick et al., "Retinal nerve fibre layer and visual function loss in glaucoma: the tipping point," British Journal of Ophthalmology, vol. 96, no. 1, pp. 47-52, 2012.

[15] M. V. Davydovskaia, M. A. Tsysar', A. N. Boǔko et al., “Damage of macular ganglion cell complex and peripapillary retinal nerve fiber layer in multiple sclerosis," Zhurnal Nevrologii i Psikhiatrii Imeni S.S. Korsakova, vol. 112, no. 2, part 2, pp. 47-51, 2012.

[16] D. C. DeBuc and G. M. Somfai, "Early detection of retinal thickness changes in diabetes using optical coherence tomography," Medical Science Monitor, vol. 16, no. 3, pp. MT15-MT21, 2010.

[17] H. L. Rao, J. G. Babu, U. K. Addepalli, S. Senthil, and C. S. Garudadri, "Retinal nerve fiber layer and macular inner retina measurements by spectral domain optical coherence tomograph in Indian eyes with early glaucoma," Eye, vol. 26, no. 1, pp. 133-139, 2012.

[18] A. M. Shahidi, G. P. Sampson, N. Pritchard et al., "Retinal nerve fibre layer thinning associated with diabetic peripheral neuropathy," Diabetic Medicine, vol. 29, no. 7, pp. e106-e111, 2012.

[19] G. A. Dissen, C. Garcia-Rudaz, A. Paredes, C. Mayer, A. Mayerhofer, and S. R. Ojeda, "Excessive ovarian production of nerve growth factor facilitates development of cystic ovarian morphology in mice and is a feature of polycystic ovarian syndrome in humans," Endocrinology, vol. 150, no. 6, pp. 29062914, 2009.

[20] J. S. Perrin, P. Y. Hervé, G. Leonard et al., "Growth of white matter in the adolescent brain: role of testosterone and androgen receptor," Journal of Neuroscience, vol. 28, no. 38, pp. 9519-9524, 2008.

[21] M. Białek, P. Zaremba, K. K. Borowicz, and S. J. Czuczwar, "Neuroprotective role of testosterone in the nervous system," Polish Journal of Pharmacology, vol. 56, no. 5, pp. 509-518, 2004.

[22] J. Pérez and D. B. Kelley, "Trophic effects of androgen: receptor expression and the survival of laryngeal motor neurons after axotomy," Journal of Neuroscience, vol. 16, no. 21, pp. 6625-6633, 1996. 


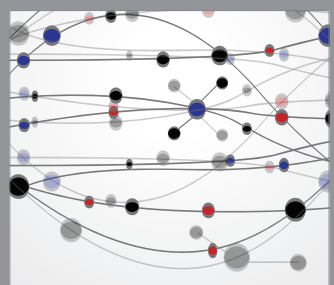

The Scientific World Journal
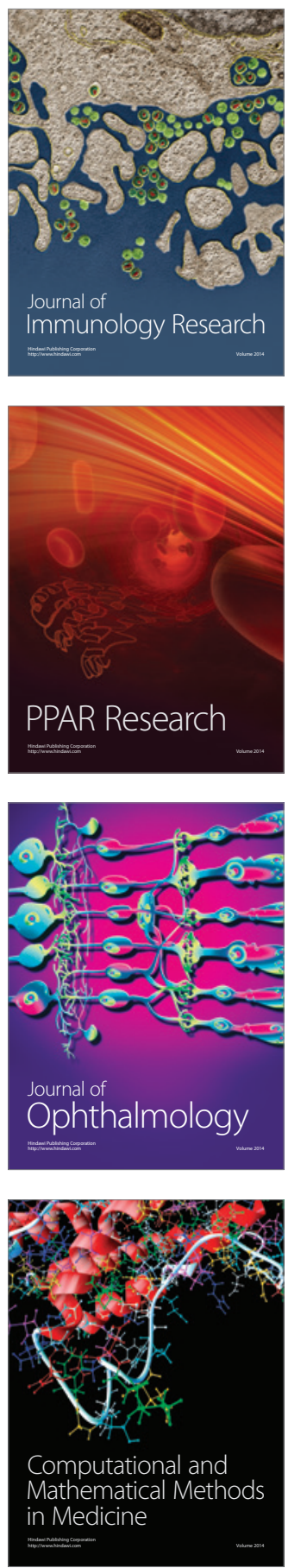

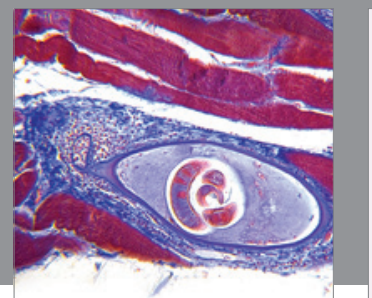

Gastroenterology

Research and Practice
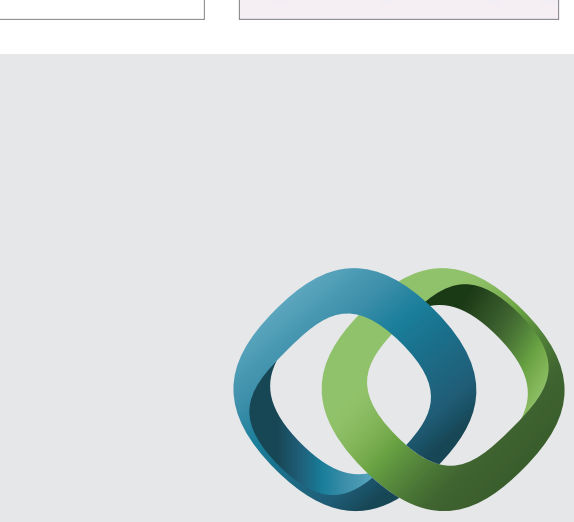

\section{Hindawi}

Submit your manuscripts at

http://www.hindawi.com
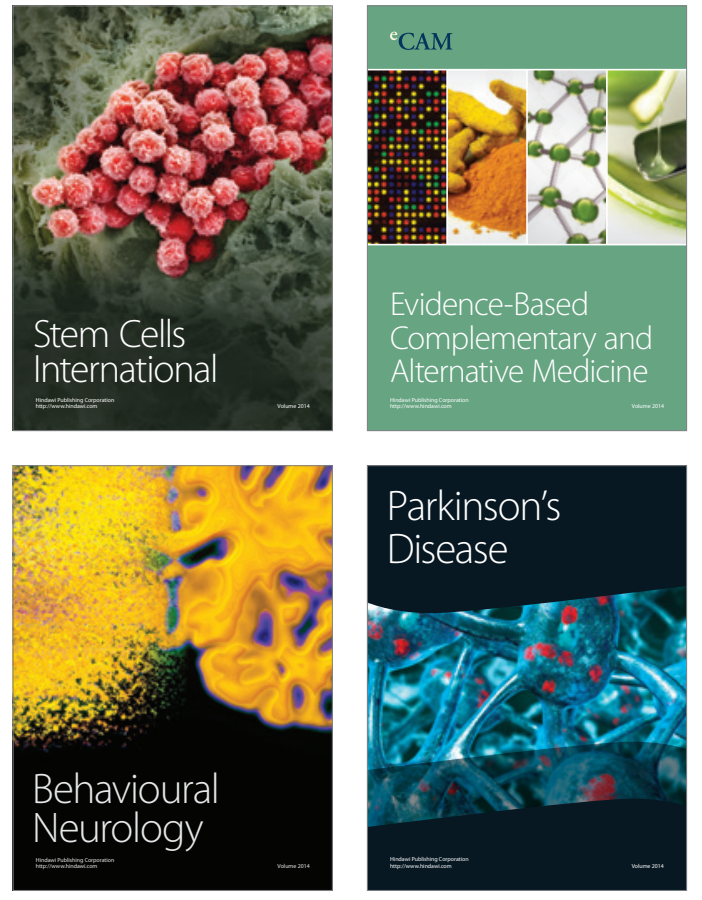
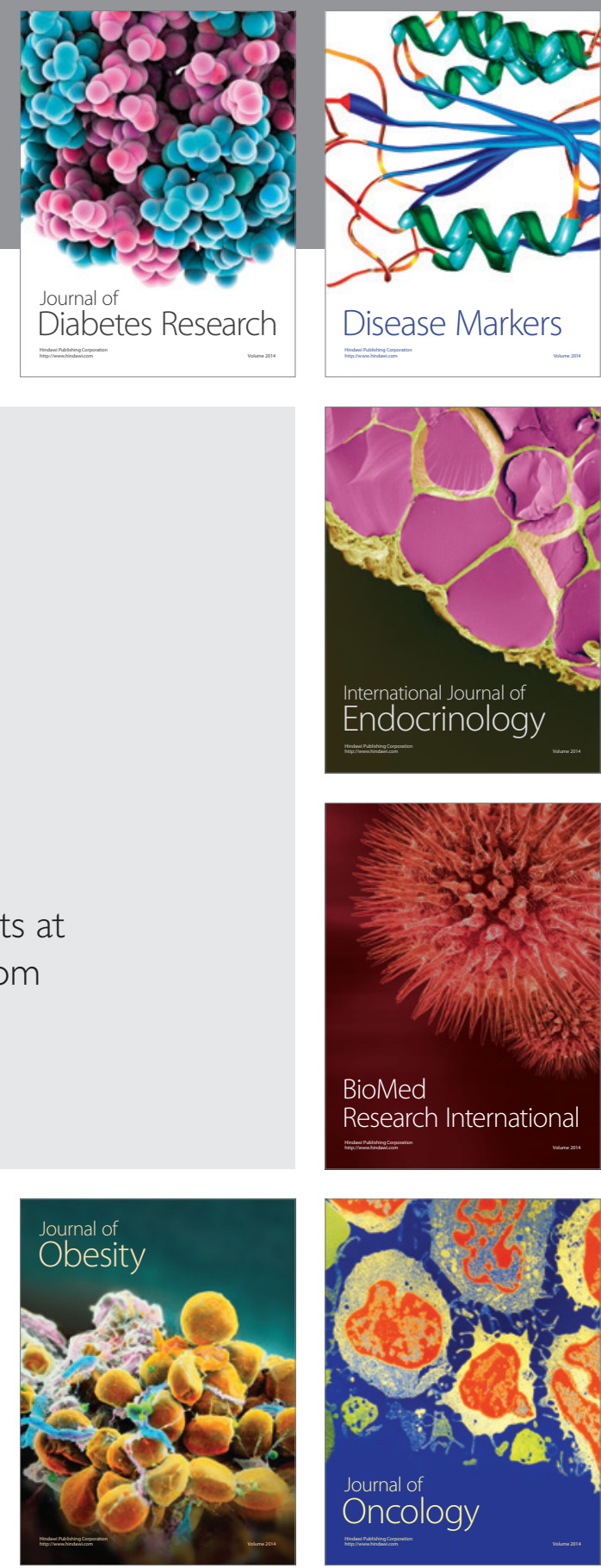

Disease Markers
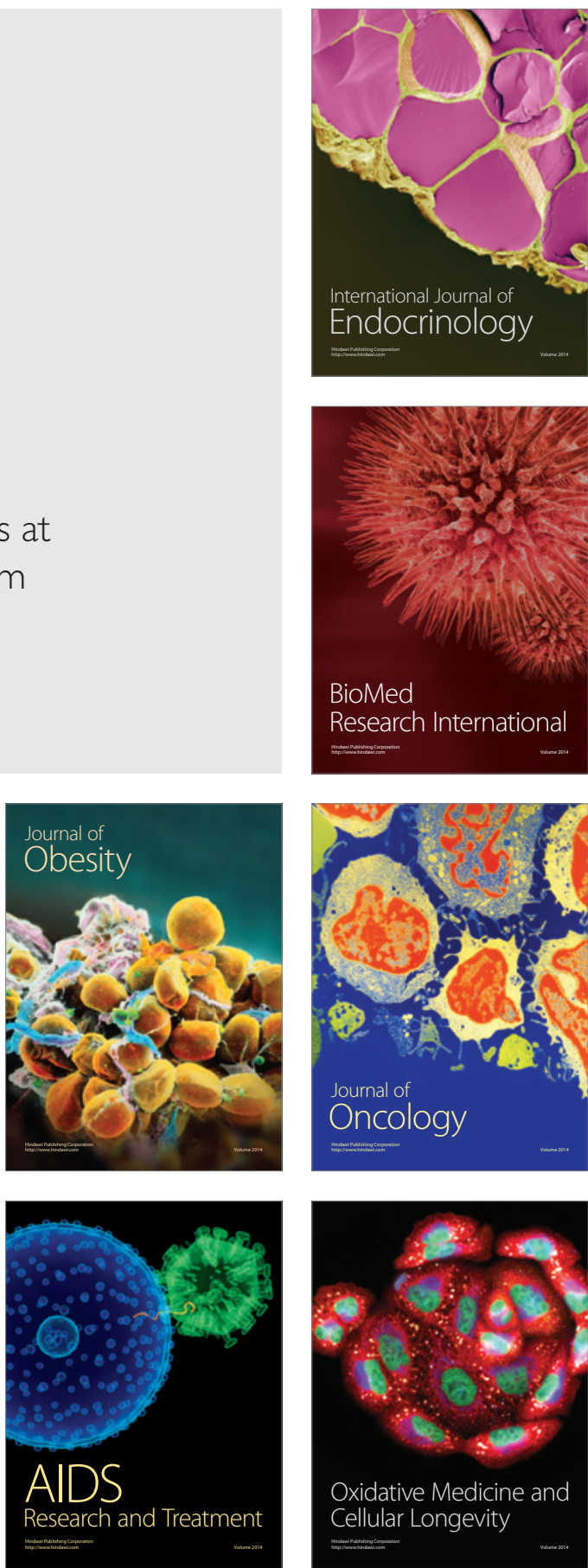